\title{
SNAKE $\alpha$-TOXIN EFFECTS ON CHOLINERGIC AND NONCHOLINERGIC RESPONSES OF APLYSIA CALIFORNICA NEURONS ${ }^{1}$
}

\author{
JOYCE K. ONO ${ }^{2}$ AND PAUL M. SALVATERRA
}

Division of Neurosciences, City of Hope Research Institute, Duarte, California 91010

\begin{abstract}
The effects of $\alpha$-toxins from Bungarus multicinctus ( $\alpha \mathrm{BuTX}$ ) and Naja naja siamensis ( $\alpha \mathrm{NTX})$ were studied on synaptic responses and on extrasynaptic responses to focally applied acetylcholine (ACh), histamine (Hm), $\gamma$-aminobutyric acid (GABA), and glutamate (glu) in neurons of the marine mollusc, Aplysia californica. Binding of ${ }^{125} \mathrm{I}-\alpha \mathrm{BuTX}$ to Aplysia ganglia homogenates was pharmacologically characterized and compared with the pharmacological sensitivity of ${ }^{125} \mathrm{I}-\alpha \mathrm{BuTX}$ binding to rat brain membrane preparations. Both $\alpha$ BuTX and $\alpha$ NTX at $10^{-5} \mathrm{M}$ reversibly inhibited the ACh-induced increase in $\mathrm{Cl}^{-}$conductance $\left(\uparrow \mathrm{G}_{\mathrm{Cl}}\right)$ without affecting $\mathrm{ACh}$ responses mediated by an increase in $\mathrm{Na}^{+}$conductance $\left(\uparrow \mathrm{G}_{\mathrm{Na}}\right)$ or an increase in $\mathrm{K}^{+}$conductance $\left(\uparrow \mathrm{G}_{\mathrm{K}}\right)$. In addition, both $\alpha$-toxins reversibly inhibited the $\uparrow \mathrm{G}_{\mathrm{Cl}}$ responses induced by $\mathrm{Hm}$ and, in some cases, glu. GABA-induced $\uparrow \mathrm{G}_{\mathrm{Cl}}$ responses were not affected by either toxin even at concentrations as high as $10^{-3} \mathrm{M}$. Both toxins also inhibited synaptic cholinergic $\uparrow \mathrm{G}_{\mathrm{Cl}}$ responses as well as the $\uparrow \mathrm{G}_{\mathrm{Cl}}$ component of postsynaptic potentials mediated by noncholinergic presynaptic neurons.

Studies of ${ }^{125} \mathrm{I}-\alpha \mathrm{BuTX}$ binding to Aplysia ganglia homogenates demonstrated the presence of a single saturable, high affinity site with a dissociation constant $\left(K_{D}\right)$ of $3.6 \times 10^{-9} \mathrm{M}$. The pharmacological profile of agents which inhibit ${ }^{125}$ I- $\alpha$ BuTX binding to Aplysia ganglia was similar to the profile of vertebrate ganglionic and brain preparations; $d$-tubocurarine, nicotine, and carbamylcholine effectively and competitively inhibit binding, whereas hexamethonium and decamethonium are less effective and noncompetitive. Strychnine and bicuculline, agents known to block responses to a variety of agonists in Aplysia, were effective competitive inhibitors of toxin binding in Aplysia and in rat brain. Strychnine is not as potent in inhibiting toxin binding to electric organ preparations. Chloride channel blockers, such as penicillin and picrotoxin, and noncholinergic agonists, such as $\mathrm{Hm}$ and glu, had no effect on toxin binding.

The $\alpha$-toxins appear to inhibit noncholinergic $\uparrow G_{\mathrm{Cl}}$ responses through a cholinergic receptor associated with the $\mathrm{Cl}^{-}$conductance mechanism for the noncholinergic agonist.
\end{abstract}

The long chain postsynaptic neurotoxins, such as $\alpha$ bungarotoxin ( $\alpha \mathrm{Bu} T \mathrm{TX})$, isolated from Bungarus multicinctus venom, and $\alpha$-Naja toxin ( $\alpha$ NTX), isolated from Naja naja siamensis venom, bind specifically to skeletal muscle and electric organ nicotinic acetylcholine (ACh) receptors (see references in Lee, 1972). In addition, both toxins inactivate the postsynaptic conductance changes induced by $\mathrm{ACh}$ at concentrations comparable to the toxin concentrations necessary to saturale binding. Phar-

\footnotetext{
${ }^{3}$ We wish to thank Dr. Richard E. McCaman for helpful comments and suggestions and the use of his equipment, Renée Foders for technical assistance, and Jill Flanagan and Margaret Anderson for typing the manuscript. This work was supported by National Institutes of Health Grants NS15583 (to R. E. M. and J. K. O.) and NS13813 (to P. M. S.)

${ }^{2}$ To whom correspondence should be addressed at Division of Neurosciences, City of Hope Research Institute, 1450 East Duarte Road, Duarte, CA 91010.
}

macological agents which antagonize or activate the neuromuscular ACh receptor also inhibit toxin binding at comparably effective concentrations (Fambrough, 1979).

The qualitative and quantitative agreement between binding studies and physiological experiments observed with vertebrate neuromuscular preparations and electric organs is lacking in comparable studies of neuronal preparations. There appears to be saturable, high affinity, specific binding of iodinated $\alpha \mathrm{BuTX}$ in a wide variety of neuronal preparations from vertebrate, invertebrate, and tissue culture sources (reviewed by Morley et al., 1979; Brown, 1979). Toxin binding in these neuronal preparations appears to be nicotinic, based on the effectiveness of nicotine and $d$-tubocurarine in inhibiting binding, but differs from the neuromuscular and electric organ binding by a relative insensitivity to blockade by decamethonium and by hexamethonium. However, the $\alpha$-neurotoxins do not antagonize reliably cholinergic responses when ap- 
plied in concentrations required to saturate toxin binding sites (Carbonetto et al., 1978). Although there have been reports of $\alpha$-neurotoxins blocking cholinergic responses in chick ciliary ganglia (Chiappinelli and Zigmond, 1978; Conti-Tronconi et al., 1979) and in cat cochlea (Fex and Adams, 1978), 1 to $10 \mu \mathrm{M}$ toxin was required to block the cholinergic responses. These concentrations of toxins are 100 times greater than those required to saturate binding in most neuronal preparations, and the possibility of contamination has been raised (Ravdin and Berg, 1979). Moreover, in sympathetic ganglia, hexamethonium antagonizes the nicotinic $\mathrm{ACh}$ response but is ineffective in inhibiting toxin binding (Brown, 1979). Thus, in contrast to toxin effects on skeletal muscle and electric organ preparations, there is a disparity between toxin binding results and physiological effects of toxin on neuronal preparations.

The central nervous system (CNS) of the mollusc, Aplysia californica, is especially suited for determining the specificity and mechanism of action of various pharmacological agents. The large neurons in Aplysia can be characterized and identified by their responses to $\mathrm{ACh}$ and to other agonists applied to the soma. It is possible, therefore, to study the specificity of a drug in terms of its effects on different conductance mechanisms and its effects on responses to particular agonists. In addition, synaptic connections mediated by identified pre- and postsynaptic neurons are available to test further the specificity of pharmacological agents on junctional receptors.

Responses to ACh in neurons of Aplysia are mediated by three pharmacologically distinct ACh receptors: (1) an excitatory response mediated by an increase in $\mathrm{Na}^{+}$ conductance $\left(\uparrow \mathrm{G}_{\mathrm{Na}}\right)$ which is blocked by hexamethonium and curare and, therefore, is similar to the vertebrate $C$ 6 or ganglionic type of nicotinic $\mathrm{ACh}$ receptor; (2) an inhibitory response mediated by an increase in $\mathrm{Cl}^{-}$conductance $\left(\uparrow \mathrm{G}_{\mathrm{Cl}}\right)$ which is insensitive to hexamethonium, is blocked by curare, and appears to be pharmacologically most like the skeletal muscle type of nicotinic $\mathrm{ACh}$ receptor; and (3) a slow inhibitory response mediated by an increase in $\mathrm{K}^{+}$conductance $\left(\uparrow \mathrm{G}_{\mathrm{K}}\right)$ which is insensitive to hexamethonium and curare but is inhibited by arecoline or low concentrations of tetraethylammonium (TEA) and, as yet, has no vertebrate counterpart (Kehoe, 1972a, b).

Previous studies using various snake venom $\alpha$-neurotoxins have produced conflicting observations on their ability to antagonize $\mathrm{ACh}$-induced responses in invertebrate neurons, including Aplysia. Szczepaniak (1974) found that $10^{-5} \mathrm{M} \alpha \mathrm{BuTX}$ did not block ACh responses in Helix, whereas long chain $\alpha$-neurotoxins from Dendroaspis viridis blocked only the $\mathrm{ACh}$ response mediated by an $\uparrow \mathrm{G}_{\mathrm{Cl}}$. Shain et al. (1974) found that $10^{-8} \mathrm{M} \alpha \mathrm{BuTX}$ reversibly blocked all three types of $\mathrm{ACh}$-induced responses in Aplysia. However, Kehoe et al. (1976) demonstrated that $\alpha \mathrm{Bu}$ TX selectively and reversibly blocked only the $\mathrm{ACh}$ response mediated by an $\uparrow \mathrm{G}_{\mathrm{Cl}}$ without affecting the $\mathrm{Na}^{+}$-dependent or $\mathrm{K}^{+}$-dependent responses.

In the present study, we investigated the pharmacological specificity of $\alpha \mathrm{BuTX}$ and of $\alpha \mathrm{NTX}$ on responses of Aplysia neurons to $\mathrm{ACh}$ as well as to several noncholin- ergic agonists. During the course of our study, we discovered that the $\alpha$-neurotoxins were selectively inhibiting chloride-mediated responses to cholinergic as well as noncholinergic agonists and transmitters. In order to elucidate further the nature of these toxin effects, we also examined the pharmacological specificity of ${ }^{125} \mathrm{I}-\alpha \mathrm{BuTX}$ binding to Aplysia ganglia homogenates. The results of these experiments indicate that the toxin binding site in Aplysia tissues is pharmacologically similar to that in vertebrate CNS and is characteristic of nicotinic $\mathrm{ACh}$ receptors.

\section{Materials and Methods \\ Experimental preparation}

Cerebral, buccal, or pleural ganglia from 300 to $500 \mathrm{gm}$ Aplysia californica (Pacific Bio-Marine, Venice, CA, and animals collected from the wild) were isolated and pinned out on the Silastic (Sylgard, Dow-Corning, Midland, MI) base of a $1.9-\mathrm{ml}$ capacity chamber. Pleural ganglion neurons previously demonstrated to respond to $\mathrm{ACh}$ with an $\uparrow \mathrm{G}_{\mathrm{Na}}$ (anterior pleural cells) and dual inhibitory response mediated by an $\uparrow \mathrm{G}_{\mathrm{Cl}}$ and $\uparrow \mathrm{G}_{\mathrm{K}}$ (medial pleural cells) (Kehoe, 1972b) were used to test the specificity of $\alpha$ BuTX and $\alpha$ NTX on the various types of ACh responses. Neurons used to test the specificity of $\alpha \mathrm{BuTX}$ and $\alpha \mathrm{NTX}$ on responses induced by various agonists were the $A$ and $B$ cluster neurons (Fredman and Jahan-Parwar, 1975) of the cerebral ganglion and several of the B type cells (Fiore and Meunier, 1975) of the buccal ganglia. These neurons respond to $\mathrm{ACh}$ with an $\uparrow \mathrm{G}_{\mathrm{Cl}}$ and, in addition, responded to $\gamma$-aminobutyric acid (GABA), histamine (Hm), and/or glutamate (glu) with an $\uparrow \mathrm{G}_{\mathrm{Cl}}$.

The effects of the neurotoxins on synaptically activated receptors involving an $\uparrow \mathrm{G}_{\mathrm{Cl}}$ component were studied in (1) the M cluster neurons (Ono and McCaman, 1980) which are identifiable followers of the histaminergic neurons (Weinreich, 1977; McCaman and McKenna, 1978) in the cerebral ganglion and (2) the B type neurons (Fiore and Meunier, 1975) of the buccal ganglia which receive convergent input from the identifiable cholinergic B4 and B5 neurons (Gardner and Kandel, 1977 ) and from the $S_{1}$ neurons (Fiore and Meunier, 1975). The transmitter utilized by the buccal $S_{1}$ neurons is not known. Pharmacological studies suggest that the $S_{1}$ transmitter is not $\mathrm{ACh}$, and the $\mathrm{S}_{\mathfrak{1}}$ neurons do not contain measurable levels of ACh, GABA, Hm, 5-hydroxytryptamine (5HT), dopamine, or octopamine (J. K. Ono, R. E. McCaman, and M. W. McCaman, unpublished).

\section{Electrodes and physiological measurements}

Neurons were impaled with double-barreled microelectrodes (10 to 30 megohms) filled with $0.5 \mathrm{M} \mathrm{K}_{2} \mathrm{SO}_{4}$. One barrel was used to record membrane potential and the other to inject current in order to control membrane voltage. Membrane input resistance was periodically monitored by passing a pulse of constant current $(0.2$ to $1.0 \mathrm{nA}$ ) through the current barrel. Responses of neurons to agonists or synaptic input were monitored at several membrane potentials to assure that alterations in response amplitude were not due to changes in reversal potential. When toxin effects were studied on synapti- 
cally activated responses, the presynaptic neurons were also impaled with double-barreled microelectrodes and activated by passing depolarizing current. Certain neurons in our study were injected with tetraethylammonium (TEA) to augment transmitter release by prolonging the presynaptic action potential or to block $\uparrow \mathrm{G}_{\mathrm{K}}$ induced by iontophoresis of agonists. TEA injection was accomplished by interbarrel iontophoresis (McCaman and McKenna, 1978). Records were photographed from storage oscilloscope traces or displayed on a chart recorder.

\section{Iontophoretic application of agonists}

Acetylcholine bromide, histamine hydrochloride, and monosodium glutamate were obtained from Sigma Chemical Co., St. Louis, MO and GABA from Calbiochem-Behring Corp., La Jolla, CA. Iontophoretic pipettes were filled with agonists at a concentration of 0.5 $\mathrm{M}$, and the $\mathrm{pH}$ was adjusted with $\mathrm{HCl}$ or $\mathrm{NaOH}$. A constant current system was used to deliver pulses of 30 to $900 \mathrm{nA}$ for periods of 20 to $200 \mathrm{msec}$. The magnitude of membrane-polarizing currents, as well as iontophoretic currents, was assessed with a bath current monitor through a virtual ground circuit. When studying the specificity of toxin effects, GABA, Hm, or glu was applied to the same neuron paired with ACh through either two separate micropipettes or a double-barreled micropipette. Multibarrel iontophoretic studies utilized a stimulus distribution system that permitted independent control of the phoretic and braking currents in each barrel. Responses to ACh could be elicited almost anywhere on the neuron soma, whereas responses to the other agonists were localized to discrete regions.

Responses mediated by an $\uparrow \mathrm{G}_{\mathrm{Cl}}$ were identified on the basis of: $(a)$ a "rapid" hyperpolarizing response at membrane potentials between -40 to $-60 \mathrm{mV}$ which reversed at a membrane potential of about -55 to $-70 \mathrm{mV}$ (Ascher et al., 1976) and $(b)$ a shift in the reversal potential of the response to a more depolarized level following perfusion with saline containing half the normal $\mathrm{Cl}^{-}$concentration or by intracellular iontophoresis of $\mathrm{Cl}^{-}$ions.

\section{Perfusion media}

Ganglia were normally bathed in artificial sea water (ASW) containing double the normal $\mathrm{Mg}^{2+}$ concentration. This ASW had the following composition (in millimolar concentrations): $\mathrm{Na}^{+}, 494 ; \mathrm{K}^{+}, 11 ; \mathrm{Mg}^{2+}, 100$; $\mathrm{Ca}^{2+}, 10 ; \mathrm{Cl}^{-}, 565 ; \mathrm{SO}_{4}{ }^{2-}, 30$; acetate, 50. The elevated divalent cation concentration diminished the amount of spontaneous activity in the ganglia by increasing spike threshold. In experiments aimed at ascertaining whether a response was mediated by $\uparrow \mathrm{G}_{\mathrm{Cl}}$, the normal $\mathrm{Cl}^{-}$concentration was decreased to half $(250 \mathrm{~mm})$ by substituting $\mathrm{NaCl}$ with sodium methyl sulfate.

The amount of toxin needed for these studies was minimized by utilizing a perfusion system that could be switched from an open to a closed (recirculating) mode. This system consisted of a peristaltic pump and a fourway Teflon valve. The total volume of recirculating perfusate was $3.9 \mathrm{ml}$. The perfusion rate throughout the experiments was $1 \mathrm{ml} / \mathrm{min}$. Control responses were taken while the bath was recirculating to assure that any dim- inution of responses was not attributable to desensitization. Control saline consisted of double strength $\mathrm{Mg}^{2+}$ ASW containing $0.1 \mathrm{mg} / \mathrm{ml}$ of bovine serum albumin (BSA) serving as a protein carrier for the toxin. A stock solution (usually $10^{-3} \mathrm{M}$ ) of $\alpha \mathrm{BuTX}$ or $\alpha \mathrm{NTX}$ was made

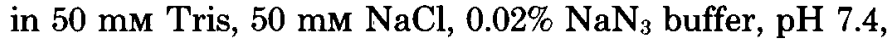
containing $1 \mathrm{mg} / \mathrm{ml}$ of BSA and diluted with control saline just prior to use. The bath concentration of Tris from the toxin stock solution was always kept considerably less than $1 \mathrm{mM}$, since Tris (10 mM) has been shown to antagonize ACh responses in Aplysia (Wilson et al., 1977; Ascher et al., 1978). Toxin was added to the bath by first withdrawing an aliquot of the bath equal to the volume of toxin stock to be added $(\sim 10 \%$ of the total volume) and then adding $300 \mu \mathrm{l}$ of a toxin solution 10 times more concentrated than the final bath concentration.

\section{Purification of $\alpha B u T X$ and $\alpha N T X$}

Crude lyophilized Bungarus multicinctus and Naja naja siamensis venoms were obtained from Miami Serpentarium (Miami, FL). $\alpha$-Toxins were purified by two CM-Sephadex ion exchange columns followed by gel filtration (Sephadex G-50) chromatography (Mebs et al., 1972). Purified toxins showed only a single component when examined by polyacrylamide gel electrophoresis in sodium dodecyl sulfate or cellulose acetate electrophoresis indicating a purity of greater than $99 \%$.

\section{${ }^{125}$ I-labeled $\alpha$-bungarotoxin binding assay}

Tissue preparation. Fresh or frozen Aplysia ganglia were homogenized in 10 volumes (w/v) of ice cold $50 \mathrm{~mm}$ Tris, $50 \mathrm{~mm} \mathrm{NaCl}, 0.02 \% \mathrm{NaN}_{3}$ buffer, pH 7.4, with a Polytron. The homogenate was sedimented at $106,000 \times$ $g$ for $30 \mathrm{~min}$ at $4^{\circ} \mathrm{C}$ in a Beckman Ti-50 rotor. The resulting pellet was resuspended in Tris $/ \mathrm{NaCl} / \mathrm{NaN}_{3}$ buffer and used for all binding assays. The resuspended homogenate was used immediately or resuspended by polytroning a once frozen and thawed sample. Rat brain membranes were prepared as described (Salvaterra and Matthews, 1980).

Binding assay. ${ }^{125} \mathrm{I}-\alpha \mathrm{BuTX}$ binding was determined essentially as described (Salvaterra and Foders, 1979) with slight modifications. Samples $(0.2 \mathrm{mg}$ of protein) were incubated in duplicate in a total volume of $0.2 \mathrm{ml}$ of Tris/ $\mathrm{NaCl} / \mathrm{NaN}_{3}$ buffer for $2 \mathrm{hr}$ at room temperature with an appropriate concentration of ${ }^{125} \mathrm{I}-\alpha \mathrm{BuTX}$ (New England Nuclear, Boston, MA; 95\% mono-iodo; specific activity, 80 to $160 \mathrm{Ci} / \mathrm{mmol}$ ). Free and bound toxin were separated by centrifugation for $5 \mathrm{~min}$ at $12,000 \times g$ in an Eppendorf microfuge with two washes of the pellet. "Nonspecific" binding was defined as the binding not blocked by a 1000 -fold excess of unlabeled $\alpha \mathrm{BuTX}$ in the incubation mixture and was subtracted from the total ${ }^{125} \mathrm{I}-\alpha \mathrm{Bu}$ TX bound. "Nonspecific" binding ranged from 2 to $20 \%$ of the total ${ }^{125}$ I- $\alpha$ BuTX bound. In a few cases, binding was studied in ASW.

For initial pharmacological characterization of the ${ }^{125} \mathrm{I}$ $\alpha \mathrm{BuTX}$ binding, ligands at various concentrations were preincubated $30 \mathrm{~min}$ before addition of ${ }^{125} \mathrm{I}-\alpha \mathrm{BuTX}$ to a final concentration of $1 \times 10^{-9} \mathrm{M}$. Inhibition constants $\left(K_{i}\right)$ and the type of inhibition were determined by 
preincubating triplicate membrane samples with or without ligands for $30 \mathrm{~min}$ at room temperature. ${ }^{125} \mathrm{I}-\alpha \mathrm{BuTX}$ was added to final concentrations of $1,2,4,8$, and $16 \mathrm{nM}$, followed by further incubation for $2 \mathrm{hr}$. Double reciprocal plots (1/bound versus 1 /toxin concentration) were analyzed by the method of least squares. Competitive inhibition was indicated by intersecting intercepts of the control plot and the sample plus ligand plot on the 1/ bound axis. Noncompetitive inhibition was indicated if the intercepts and slopes of the control and experimental plots were significantly different (Student's $t$ test, $p<$ $0.05)$

The various ligands tested for their ability to inhibit ${ }^{125} \mathrm{I}-\alpha \mathrm{BuTX}$ binding were nicotine, $d$-tubocurarine chloride, carbamylcholine chloride, decamethonium bromide, hexamethonium bromide, neostigmine bromide, picrotoxin, atropine sulfate, histamine dihydrochloride, strychnine hydrochloride, and penicillin $G$ (all from Sigma Chemical Co., St. Louis, MO), and L-(+)-glutamic acid (Eastman, Rochester, NY), ouabain (strophanthin G; Calbiochem, La Jolla, CA), and bicuculline methiodide (Pierce, Rockford, IL).

Protein was determined by the method of Lowry et al. (1951) using BSA as a standard.

\section{Results}

\section{Effects of $\alpha B u T X$ and $\alpha N T X$}

ACh-induced responses. Both $\alpha \mathrm{BuTX}$ and $\alpha \mathrm{NTX}$ specifically antagonized the $\uparrow \mathrm{G}_{\mathrm{Cl}}$ responses elicited by focal application of $A C h$. In Figure $1 A$, the $\uparrow G_{\mathrm{Na}}$ response of an anterior pleural neuron (Kehoe, 1972b) appears to be unaffected by $8 \times 10^{-6} \mathrm{M} \alpha \mathrm{NTX}$. $\alpha$ BuTX at $1 \times 10^{-5} \mathrm{M}$ also had no effect on this response. In contrast, the twocomponent inhibitory response of a medial pleural neuron is affected as shown in Figure $1 B$. The fast component mediated by $\uparrow \mathrm{G}_{\mathrm{Cl}}$ is completely blocked by $\alpha \mathrm{NTX}$ (and $\alpha B u T X$, data not shown) while the slower component mediated by $\uparrow \mathrm{G}_{\mathrm{K}}$ is unaffected. The toxin block of the $\uparrow G_{\mathrm{Cl}}$ component occurs at a membrane potential of either -50 or $-70 \mathrm{mV}$ and is slowly reversible. These results are similar to those of Kehoe and co-workers (1976) for the effects of $\alpha \mathrm{BuTX}$ on ACh responses.

Noncholinergic agonist-induced responses. $\alpha \mathrm{Bu} T \mathrm{TX}$ and $\alpha$ NTX will also antagonize $\uparrow \mathrm{G}_{\mathrm{Cl}}$-mediated responses initiated by focal application of noncholinergic agonists. Figure 2 illustrates the effect of $\alpha$ NTX on ACh- and Hminduced $\uparrow G_{C l}$ responses in a cerebral $A$ neuron. This neuron has been shown previously to respond to both $\mathrm{ACh}$ and $\mathrm{Hm}$ with a two-component inhibitory response mediated by an $\uparrow \mathrm{G}_{\mathrm{Cl}}$ and an $\uparrow \mathrm{G}_{\mathrm{K}}$ (Gruol and Weinreich, 1979). The $\uparrow G_{K}$ component has been diminished by intracellular injection of TEA ions since this component is very large relative to the $\uparrow \mathrm{G}_{\mathrm{Cl}}$ component. Furthermore, responses to $\mathrm{ACh}$ and $\mathrm{Hm}$ were collected at the $\mathrm{K}^{+}$ reversal potential $(-85 \mathrm{mV})$ for this neuron and represent an outward flow of $\mathrm{Cl}^{-}$.

Both the ACh- and $\mathrm{Hm}$-induced $\uparrow \mathrm{G}_{\mathrm{Cl}}$ responses were blocked within 5 min after bath application of $1 \times 10^{-5}$ M $\alpha$ NTX. This inhibition of the $\uparrow \mathrm{G}_{\mathrm{Cl}}$ response could be reversed after washing for $1.5 \mathrm{hr}$. $\alpha \mathrm{BuTX}$ and $\alpha \mathrm{NTX}$ were also observed to block $\uparrow G_{\mathrm{Cl}}$ responses initiated by iontophoresis of glu. This effect was variable, however, since some glu-initiated $\uparrow \mathrm{G}_{\mathrm{Cl}}$ responses were completely
CONTROL

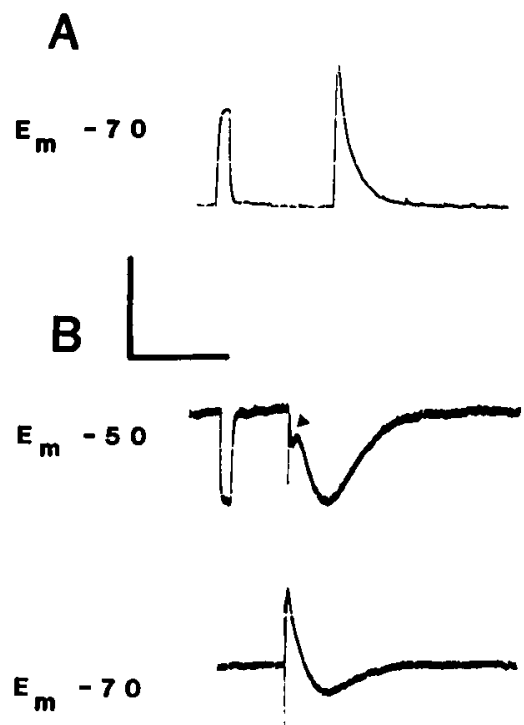

$\alpha \mathbf{N} \mathrm{X}$
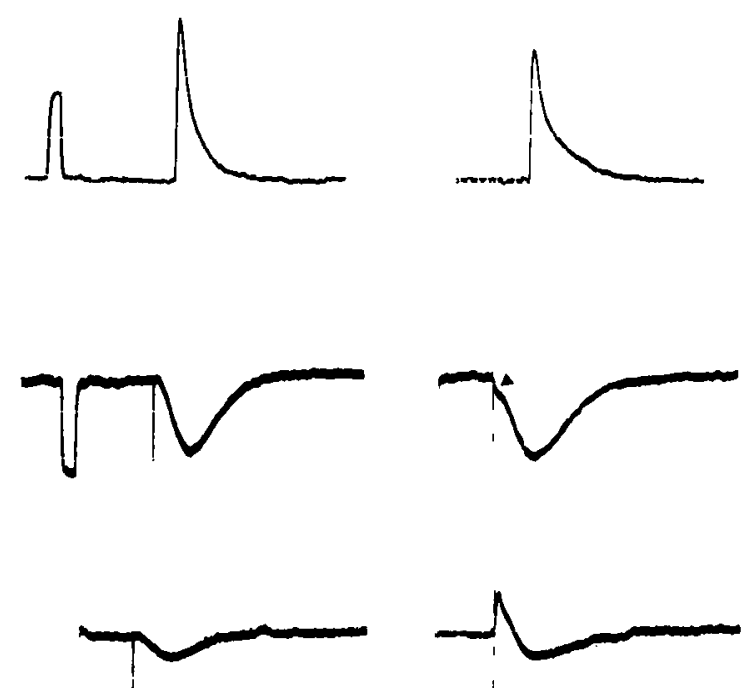

W A S H

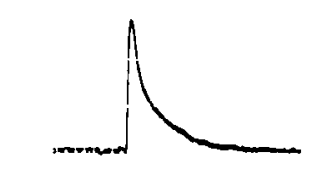

Figure 1. Effect of $\alpha$-neurotoxins on ACh responses involving different ionic conductances. $A$, Anterior cell from the left pleural ganglion previously shown by Kehoe (1972b) to respond to ACh with an $\uparrow G_{\mathrm{Na}}$. The $\uparrow \mathrm{G}_{\mathrm{Na}} \mathrm{ACh}$ response is not affected by a 1-hr perfusion of $8 \times 10^{-6} \mathrm{M} \alpha \mathrm{NTX}$. The input resistance test pulse is $1.0 \mathrm{nA}$. ACh was applied by a pressure pulse of 40 psi for $7 \mathrm{msec}$, ejecting a 4-pl droplet of $10^{-4} \mathrm{M}$ ACh. Calibration: $10 \mathrm{mV} ; 10 \mathrm{sec}$. B, Medial pleural neuron shown by Kehoe (1972a, b) to respond to $\mathrm{ACh}$ with a two-component inhibition involving an $\uparrow \mathrm{G}_{\mathrm{Cl}}$ (arrow) and an $\uparrow \mathrm{G}_{\mathrm{K}}$. At a membrane potential ( $E_{m}$ ) of $-50 \mathrm{mV}$, the $\mathrm{Cl}^{-}$component is hyperpolarizing; at $E_{m}=-70 \mathrm{mV}$, the $\mathrm{Cl}^{-}$component is reversed and depolarizing. Only the $\mathrm{Cl}^{-}$component is blocked after $1 \mathrm{hr}$ in $8 \times 10^{-6} \mathrm{M} \alpha \mathrm{N}^{\prime} \mathrm{TX}$ with no change in cell input resistance $(0.2 \mathrm{nA}$ current pulse). This inhibition is reversed after $1 \mathrm{hr}$ washing with toxin-free saline. ACh iontophoresed with a current pulse of $600 \mathrm{nA}$ for $50 \mathrm{msec}$. Calibration: $4 \mathrm{mV}$; $10 \mathrm{sec}$. Data for both anterior and medial pleural neurons were collected simultaneously from the same ganglion. 
CONTROL
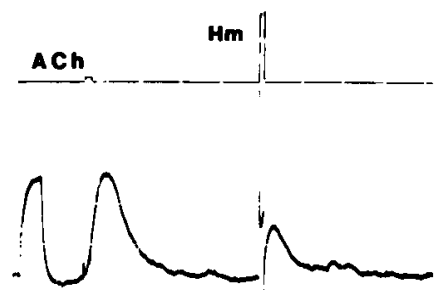

O NTX
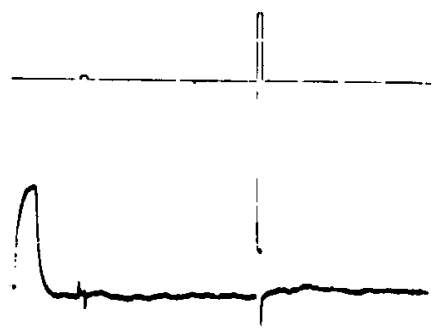

WASH

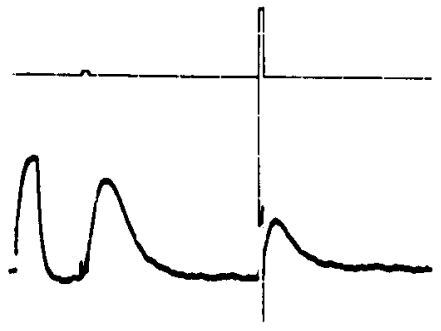

1

Figure 2. Effect of $\alpha$-neurotoxins on $\uparrow \mathrm{G}_{\mathrm{Cl}}$ responses induced by $\mathrm{ACh}$ and by $\mathrm{Hm}$. Upper traces, Bath current monitor trace of iontophoretic pulses. Lower traces, Responses to iontophoretic ejections of ACh and Hm. Control figure depicts the reversed $\uparrow \mathrm{G}_{\mathrm{Cl}}$ responses to iontophoretically applied $\mathrm{ACh}$ and $\mathrm{Hm}$ in a cerebral A cell. After $20 \mathrm{~min}$ in $1 \times 10^{-5} \mathrm{M} \alpha \mathrm{NTX}$, both ACh und $\mathrm{Hm} \uparrow \mathrm{G}_{\mathrm{Cl}}$ responses are eliminated. The responses return after $1.5 \mathrm{hr}$ of washing with toxin-free saline. ACh was applied with a 30 $\mathrm{nA}, 50 \mathrm{msec}$ pulse of current; $\mathrm{Hm}$ with $840 \mathrm{nA}$ of current for $120 \mathrm{msec}$. $E_{m}$ was held at $-85 \mathrm{mV}$ (see text). Calibration: $1 \mu \mathrm{A}, 4 \mathrm{mV}$; $2 \mathrm{sec}$.

blocked by $1 \times 10^{-5} \mathrm{M}$ toxin while others were only partially affected. In all cases, the same neurons responded to $\mathrm{ACh}$ application with an $\uparrow \mathrm{G}_{\mathrm{Cl}}$ which was completely blocked by either toxin.

In contrast to the effects of $\alpha$-toxins on $\mathrm{ACh}$ and $\mathrm{Hm}$ responses, GABA-induced $\uparrow \mathrm{G}_{\mathrm{Cl}}$ responses were unaffected by either toxin at concentrations up to $1 \times 10^{-3}$ $M$ even though the same neurons had $A C h$-initiated $\uparrow \mathrm{G}_{\mathrm{Cl}}$ responses that were completely blocked (also observed by Yarowsky and Carpenter, 1978).

Synaptic cholinergic $\uparrow G_{C l}$ responses. Synaptically evoked cholinergic responses mediated by an $\uparrow \mathrm{G}_{\mathrm{Cl}}$ were also blocked by $\alpha$ NTX or $\alpha$ BuTX. In Figure $3 A$, the identifiable cholinergic neuron, $\mathrm{B} 4$, in the buccal ganglion mediates an inhibitory postsynaptic potential (IPSP) involving an $\uparrow \mathrm{G}_{\mathrm{Cl}}$ in an unidentified buccal follower (B?). The cholinergic IPSP was blocked after a 1-hr exposure to $\alpha \mathrm{NTX}$, and the block was partially reversed after washing for $4.5 \mathrm{hr}$.

Noncholinergic synaptic responses. This same buccal follower, B? (Fig. 3B), also receives convergent synaptic input from several buccal neurons called the $S_{1}$ 's (Fiore and Meunier, 1975). As shown in the neuronal circuit depicted in Figure 3, the cholinergic neuron (B4) also receives synaptic input from the $S_{1}$ 's. Figure $3 B$ illustrates the excitatory PSP (EPSP) and the inhibitoryexcitatory PSP (IEPSP) evoked in B4 and $B$ ?, respectively, by action potentials in the $S_{1}$ neuron. Only the fast inhibitory component of the $S_{1} \rightarrow B$ ? IEPSP is blocked by $5 \times 10^{-6} \mathbf{M} \alpha \mathrm{NTX}$. Toxin did not affect the input resistance of any of the neurons studied, the $S_{1} \rightarrow B 4$ EPSP, or the excitatory component in the $S_{1} \rightarrow B$ ? IEPSP. The fast inhibitory response appears to be mediated by $\uparrow G_{\mathrm{Cl}}$ since its reversal potential is approximately $-60 \mathrm{mV}$, and this reversal potential can be raised to a more depolarized level by decreasing the external $\mathrm{Cl}^{-}$concentration or by intracellular injection of $\mathrm{Cl}^{-}$ions. The transmitter released by the $S_{1}$ 's is not ACh since (a) B4 responds to $\mathrm{ACh}$ with an $\uparrow \mathrm{G}_{\mathrm{Cl}}$ (Gardner, 1977), whereas the $S_{1}$-mediated EPSP appears to involve an $\uparrow \mathrm{G}_{\mathrm{Na}}$ which is not antagonized by hexamethonium (J. K. Ono and R. E. McCaman, unpublished) and (b) $\mathrm{ACh}$ is not detectable in the $S_{1}$ 's (J. K. Ono and R. E. McCaman, unpublished).

Another synaptically mediated $\uparrow \mathrm{G}_{\mathrm{Cl}}$ response blocked by toxin is demonstrated in Figure 4 . The IEPSP in the M-1 neuron of the cerebral ganglion is mediated by a monosynaptic connection from an identified histaminecontaining neuron (McCaman and McKenna, 1978). $\alpha$ BuTX blocked the inhibitory component which has been shown previously to involve an $\uparrow \mathrm{G}_{\mathrm{Cl}}$ (McCaman and McKenna, 1978). This inhibition of the $\uparrow G_{C l}$ component by toxin was reversible after $1 \mathrm{hr}$ of washing.

The $\alpha$-neurotoxins do not block all synaptic $\uparrow \mathrm{G}_{\mathrm{Cl}}$ responses induced by the histamine-containing neuron, HN. Figure 5 demonstrates that another one of the $\mathrm{HN}$ followers, $\mathrm{M}-2$, responds to action potentials in $\mathrm{HN}$ with an IEPSP. This response appears to be similar to the IEPSP observed in M-1 (Fig. 4). The $\uparrow \mathrm{G}_{\mathrm{Cl}}$ component of M-2, however, is not blocked by toxin, even after $5 \mathrm{hr}$ of constant perfusion with $2 \times 10^{-5} \mathrm{M} \alpha \mathrm{NTX}$. The two HN followers, $M-1$ and $M-2$, are adjacent to one another on the ventromedial surface of the anterior tentacular nerve. Figure 5 demonstrates that the $\uparrow \mathrm{G}_{\mathrm{Cl}}$ component is blocked only in $M-1$, whereas the $\uparrow G_{\mathrm{Cl}}$ component of $M$ 2 is not affected. In some M-1 followers, a fast excitatory component is unmasked (Fig. 5) by blocking the $\uparrow \mathrm{G}_{\mathrm{Cl}}$ response with toxin or with $d$-tubocurarine. Both M-1 and $\mathrm{M}-2$ respond to $\mathrm{ACh}$ iontophoresed onto their soma. However, $\mathrm{M}-1$ responds with an $\uparrow \mathrm{G}_{\mathrm{Cl}}$, which is blocked by toxin (right panel in Fig. 5), whereas $\mathrm{M}-2$ responds to ACh with an $\uparrow \mathrm{G}_{\mathrm{Na}}$ inducing action potentials in $\mathrm{M}-2$ (as evidenced by Fig. 5), and this excitatory ACh response is not affected by the $\alpha$-toxins.

\section{${ }^{125} I$ - $\alpha B u T X$ binding studies}

Levels and affinity of ${ }^{125} \mathrm{I}-\alpha B u T X$ binding. ${ }^{125} \mathrm{I}-\alpha \mathrm{BuTX}$ binding to Aplysia homogenates indicated the presence of a single, saturable high affinity site. Figure 6 shows a representative binding isotherm using fresh whole nervous system. The inset is a Scatchard plot of the binding data. In three separate experiments using fresh or frozen ganglia, we have obtained linear Scatchard plots with maximal binding $\left(B_{\max }\right.$ ) of $117.3 \pm 29.1 \mathrm{fmol} / \mathrm{mg}$ of pro- 
A
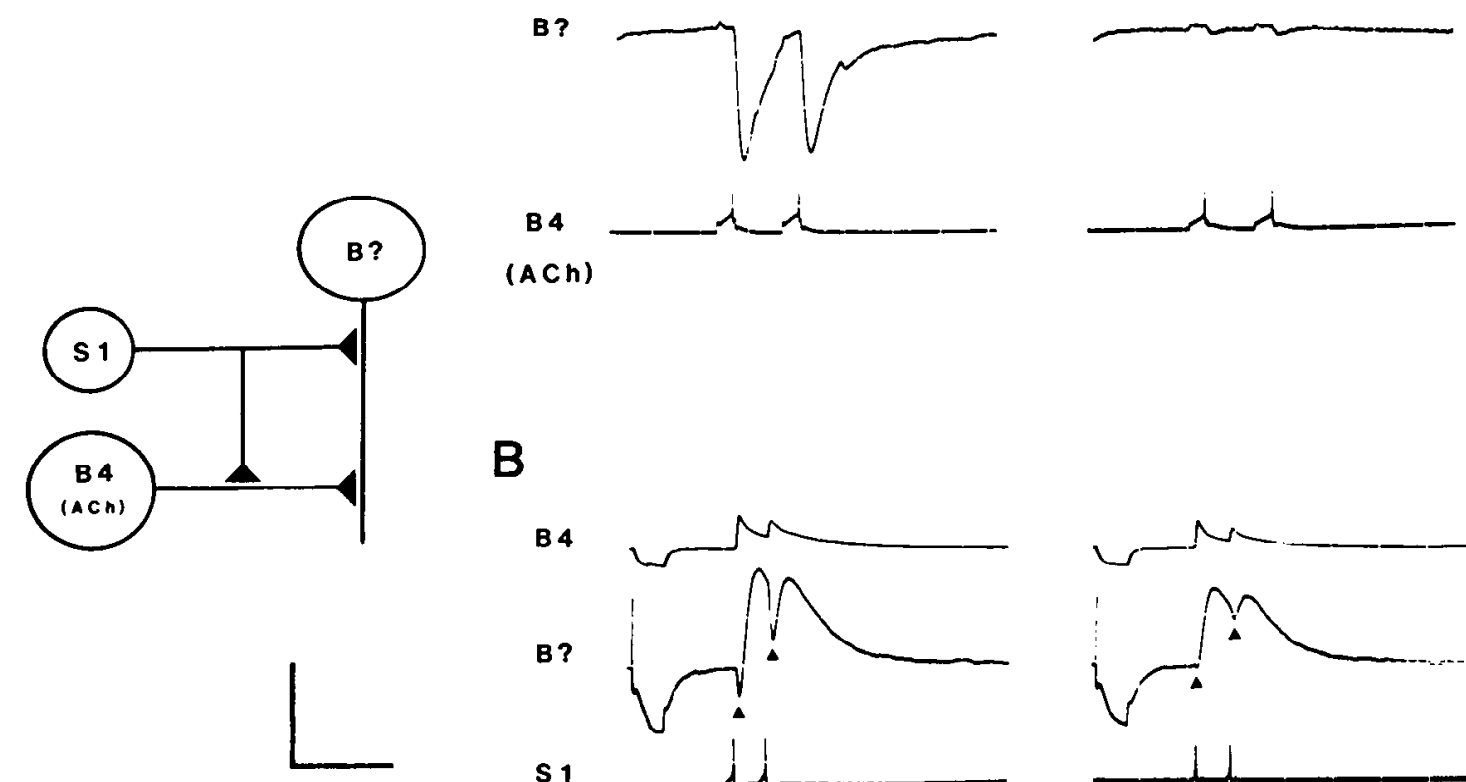

$B 4$
$(A C h)$
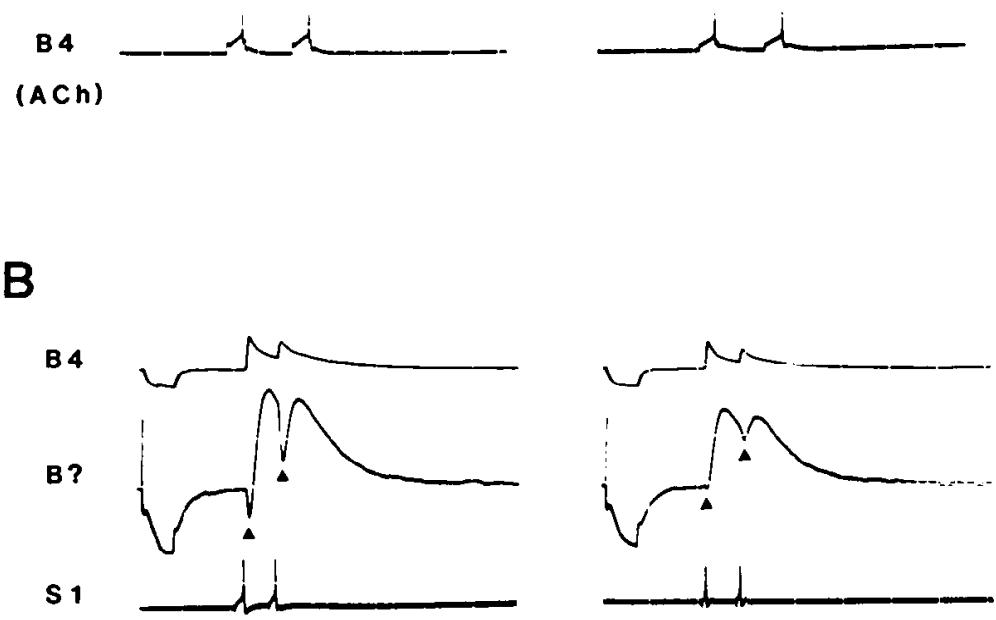

Figure 3. Effect of $\alpha$-neurotoxins on synaptically evoked cholinergic and noncholinergic postsynaptic responses. A diagram of the neuronal circuit in the buccal ganglion is depicted on the left. Data for this figure were collected in the same preparation. The $S_{1}$ and B4 neurons were injected with TEA to prolong the presynaptic action potential and, therefore, augment the postsynaptic responses. $A, 5 \times 10^{-6} \mathrm{M} \alpha \mathrm{NTX}$ blocks the cholinergic IPSP involving an $\uparrow \mathrm{G}_{\mathrm{Cl}}$ in an unidentified buccal follower (B?). Weak electrotonic coupling between B4 and B? is revealed after elimination of the $\uparrow G_{\mathrm{Cl}}$ response. Elimination of the cholinergic IPSP's required $1 \mathrm{hr}$ of perfusion with $5 \times 10^{-6} \mathrm{M} \alpha \mathrm{NTX} . E_{m}$ of B? $=-54 \mathrm{mV}$. Calibration: $200 \mathrm{mV}$ for B4; $4 \mathrm{mV}$ for B?; $0.4 \mathrm{sec}$. $B, \alpha \mathrm{NTX}$ blocks the $\uparrow G_{\mathrm{Cl}}$ component mediated by the noncholinergic $S_{1}$ neurons on $B$ ? (same cell in $A$ ) without affecting other types of PSP's. The $\uparrow \mathrm{G}_{\mathrm{Cl}}$ component in $\mathrm{B}$ ? was eliminated after a $0.5-\mathrm{hr}$ perfusion of $5 \times 10^{-6} \mathrm{M}$ toxin and returned after $3 \mathrm{hr}$ of washing. No alteration of input resistance occurred during exposure to toxin. $E_{m}$ of $\mathrm{B} 4=-60 \mathrm{mV} ; \mathrm{B}$ ? $=-54 \mathrm{mV}$. Input resistance pulse for $\mathrm{B} 4=0.4 \mathrm{nA}$; for $\mathrm{B}$ ? $=0.2 \mathrm{nA}$. Calibration: $20 \mathrm{mV}$ for $\mathrm{B} 4,4 \mathrm{mV}$ for $\mathrm{B}$ ?, and $200 \mathrm{mV}$ for $\mathrm{S}_{1} ; 0.4$ sec.

CONTROL

$\alpha$ Bu T X

M 1
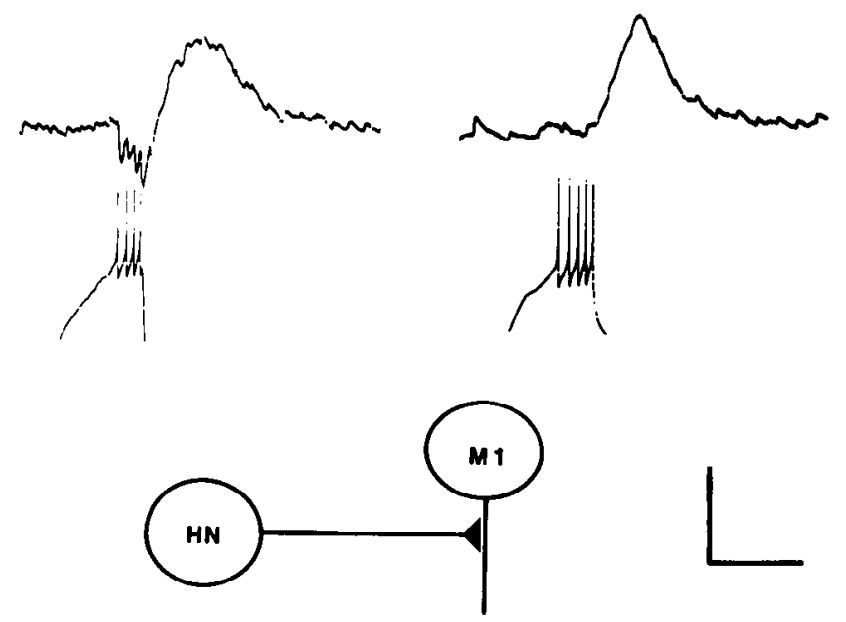

Figure 4. Inhibition of the $\mathrm{Cl}^{-}$component of a multicomponent PSP mediated by an identified histaminergic neuron (HN). The fast IPSP's in the follower neuron, $M-1$, are blocked after a l-hr perfusion with $8 \times 10^{-6} \mathrm{M} \alpha \mathrm{BuTX}$. This inhibition is reversed after $3 \mathrm{hr}$ washing (not shown). Only the $\uparrow \mathrm{G}_{\mathrm{Cl}}$ component of this response is affected, with no change in M-1 input resistance. $E_{m}$ of M-1 $=-52 \mathrm{mV}$. Calibration: $4 \mathrm{mV}$ for M-1; 40 $\mathrm{mV}$ for $\mathrm{HN}$; $0.4 \mathrm{sec}$. tein and an apparent dissociation constant $\left(K_{D}\right)$ of 3.6 $\pm 1.3 \times 10^{-9} \mathrm{M}$ (mean $\left.\pm \mathrm{SEM}\right)$.

Pharmacological characterization of ${ }^{125} I-\alpha B u T X$ binding. Figure $7, A$ to $C$ shows the concentration-dependent ability of various ligands to inhibit ${ }^{125} \mathrm{I}-\alpha \mathrm{BuTX}$ binding to Aplysia membranes. The data from these graphs were used to select an appropriate concentration of inhibitory ligand for double reciprocal analysis. Classical cholinergic agonists and antagonists were found to be most effective in inhibiting ${ }^{125} \mathrm{I}-\alpha \mathrm{BuTX}$ binding. The noncholinergic agonists, $\mathrm{Hm}$ and glu, as well as the $\mathrm{Cl}^{-}$ channel blockers, penicillin $\mathrm{G}$ and picrotoxin, showed no effect on toxin binding at concentrations up to $1 \mathrm{mM}$. In contrast to the results of Shain et al. (1974), we find no effect of the $\left(\mathrm{Na}^{+}, \mathrm{K}^{+}\right)$-ATPase inhibitor, ouabain, at concentrations up to $1 \mathrm{mM}$.

The $K_{i}$ 's of the various ligands were calculated from double reciprocal plots, as described under "Materials and Methods," and are summarized in Table I for Aplysia and rat brain membranes. The results for both of these preparations are strikingly similar. All ligands were competitive inhibitors of ${ }^{125} \mathrm{I}-\alpha \mathrm{BuTX}$ binding except decamethonium and hexamethonium which were noncompetitive. Both unlabeled $\alpha \mathrm{BuTX}$ and $\alpha$ NTX have affinities in the nanomolar range. The nicotinic agonists, nicotine and carbamylcholine, as well as the classical nicotinic antagonist, $d$-tubocurarine, have micromolar affin- 


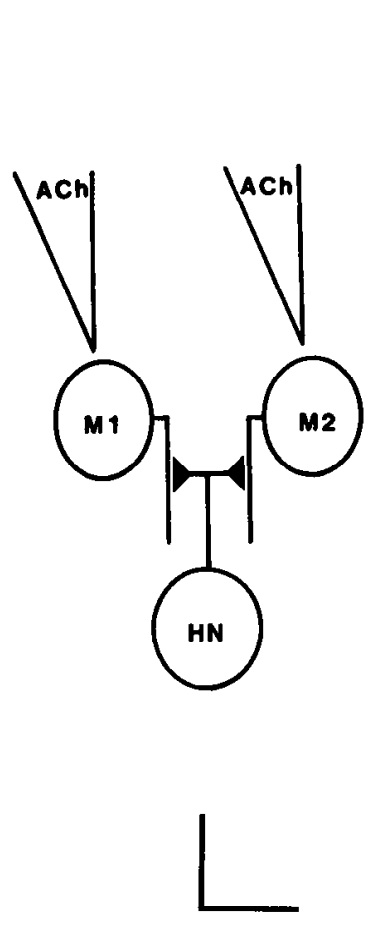

CONTROL

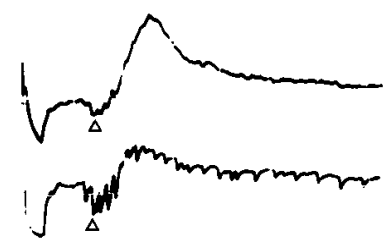

HN
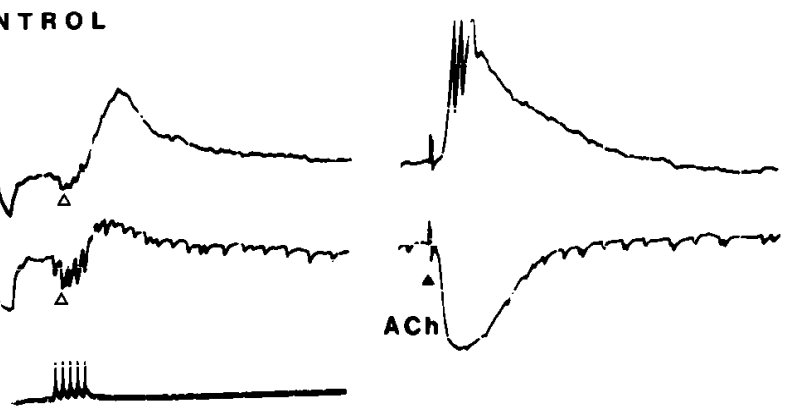

$\propto N T X$

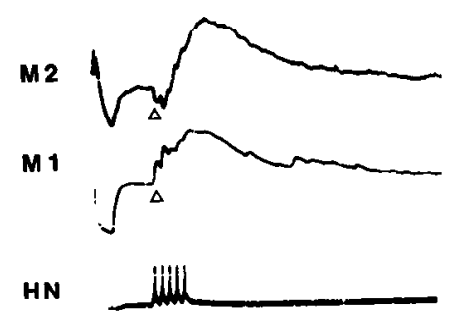

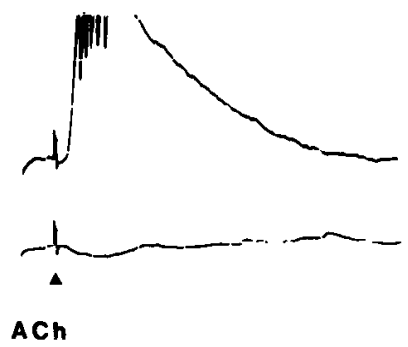

Figure 5. Demonstration that not all $\uparrow \mathrm{G}_{\mathrm{Cl}}$ responses mediated by the histaminergic neuron, $\mathrm{HN}$, are blocked by $\alpha$-neurotoxins. Experimental paradigm is depicted to the left of the figure. The control figure demonstrates that both M-1 (see also Fig. 4) and M-2 respond to action potentials in the $\mathrm{HN}$ with an IEPSP (open arrows indicate $\uparrow \mathrm{G}_{\mathrm{Cl}}$ component of the synaptic response). However, M-1 responds to ACh applied to the soma (solid arrow) with an $\uparrow \mathrm{G}_{\mathrm{Cl}}$, whereas $\mathrm{M}-2$ responds to $\mathrm{ACh}$ with an $\uparrow \mathrm{G}_{\mathrm{Na}}$ (tops of M-2 action potentials cut off by oscilloscope screen). After a $0.5-\mathrm{hr}$ exposure to $1 \times 10^{-5} \mathrm{M} \alpha \mathrm{NTX}$, the $\uparrow \mathrm{G}_{\mathrm{Cl}}$ component of the M-1 synaptic response and the response to $\mathrm{ACh}$ are blocked, whereas the $\uparrow \mathrm{G}_{\mathrm{Cl}}$ component in M-2 is not affected. Note that elimination of the $\uparrow \mathrm{G}_{\mathrm{Cl}}$ in this particular M-1 reveals an underlying EPSP; no change in $E_{m}$ occurs during perfusion with toxin. No change in input resistance (current pulse of $0.2 \mathrm{nA}$ for both cells) occurs during toxin perfusion. $E_{m}$ of $\mathrm{M}-1=-50 \mathrm{mV} ; E_{m}$ of $\mathrm{M}$ $2=-40 \mathrm{mV}$. ACh was applied by iontophoretic pulses of $600 \mathrm{nA}$ for $20 \mathrm{msec}$. Calibration: $10 \mathrm{mV}$ for $\mathrm{M}-1$ and $\mathrm{M} \cdot 2 ; 200 \mathrm{mV}$ for HN; 2 sec.

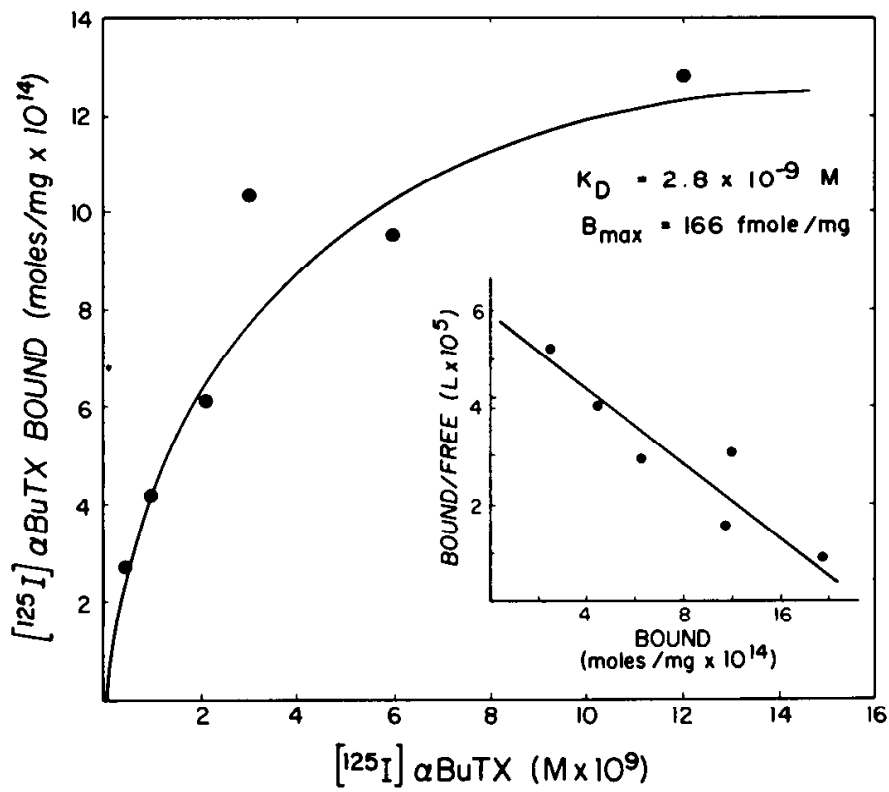

Figure 6. Representative binding isotherm of ${ }^{125} \mathrm{I}-\alpha \mathrm{BuTX}$ to an Aplysia ganglia homogenate. The curve represents specific binding (total binding minus binding not displaced by a 100 fold excess of unlabeled $\alpha \mathrm{BuTX}$ ) for fresh whole nervous system homogenates. "Nonspecific" binding ranged from 2 to $20 \%$ of the total binding. The inset is a Scatchard plot of this binding curve. See "Materials and Methods" for experimental details. ities. A surprising finding was the competitive nature, as well as relatively high affinity, of strychnine and bicuculline binding. These agents are usually considered as antagonists of glycine- and GABA-induced responses, respectively. Atropine, a muscarinic antagonist, and neostigmine, usually considered an acetylcholinesterase inhibitor, also displayed some affinity for the toxin binding site.

While the pharmacological profiles of the ${ }^{125} \mathrm{I}-\alpha \mathrm{BuTX}$ binding sites are similar for Aplysia and rat brain, several distinct differences were noted when comparing these results to results obtained with peripheral electric organ (see Table I). Nicotine and carbamylcholine appear to bind to neuronal membranes with higher affinity. Strychnine is approximately 10 -fold more effective in inhibiting neuronal ${ }^{125} \mathrm{I}-\alpha \mathrm{BuTX}$ binding. Perhaps one of the most striking pharmacological differences between peripheral electric organ and neuronal binding sites is the higher affinity of the former for decamethonium and hexamethonium.

\section{Discussion}

Our results demonstrating the specificity not only of $\alpha \mathrm{BuTX}$ but also of $\alpha$ NTX for ACh responses mediated by an $\uparrow G_{\mathrm{Cl}}$ confirm and support the results obtained by Kehoe et al. (1976) with $\alpha$ BuTX. These results contradict the earlier observations of Shain et al. (1974), which 

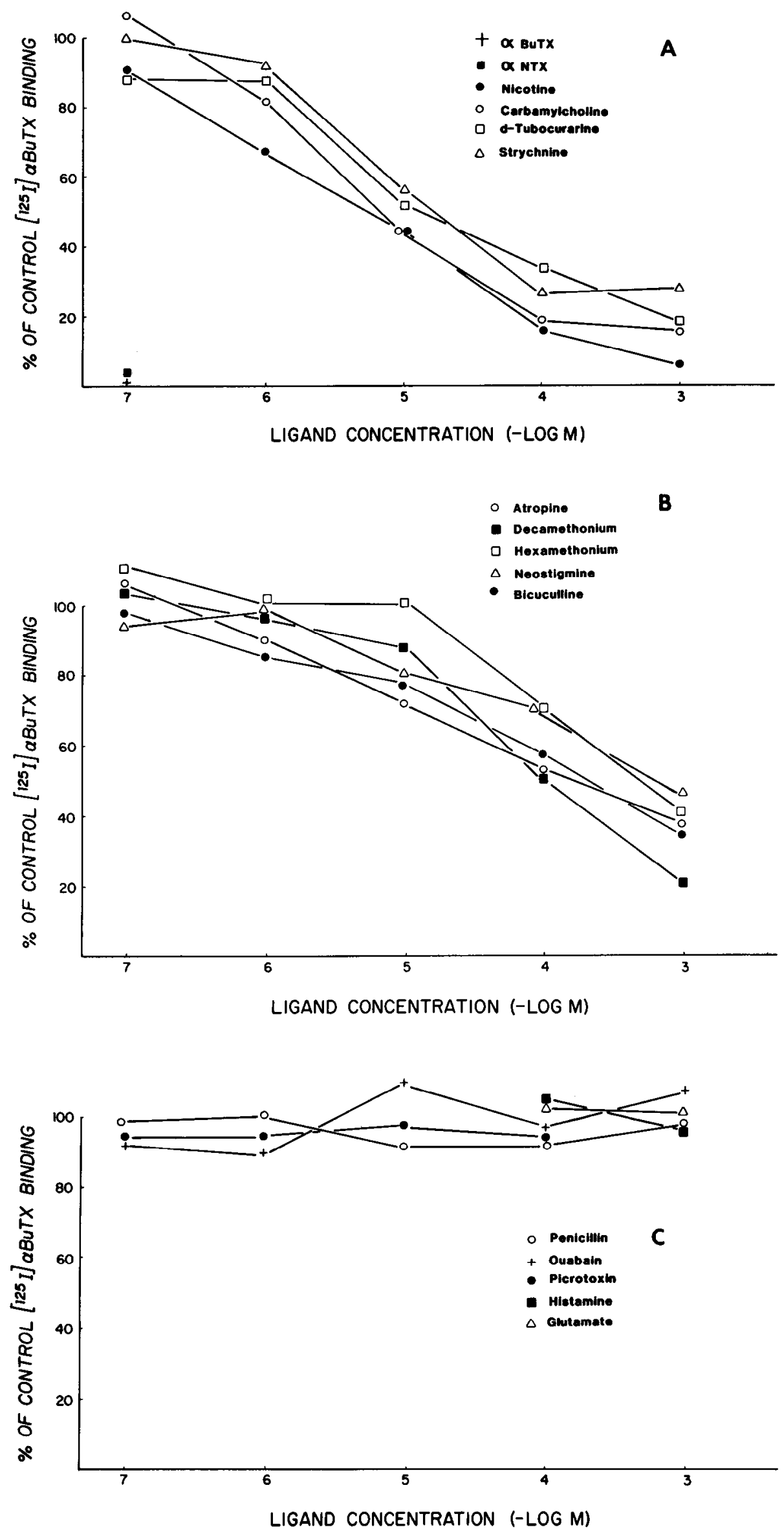
TABLE I

Ability of various ligands to prevent ${ }^{125} I-\alpha B u T X$ binding to Aplysia and rat membranes

\begin{tabular}{|c|c|c|c|c|c|}
\hline \multirow{2}{*}{ Ligand } & \multirow{2}{*}{ Concentration $^{a}$} & \multicolumn{2}{|c|}{ Inhibition Constant, $K_{i}^{a}$} & & \multirow{2}{*}{$\begin{array}{l}\text { Electri } \\
\text { Organ }^{\circ}\end{array}$} \\
\hline & & Aplysia Ganglia & Rat Brain & & \\
\hline & $\mathbf{M}$ & \multicolumn{2}{|c|}{$\mu M$} & & \\
\hline$\alpha \mathrm{BuTX}$ & $2.5 \times 10^{-9}$ & $0.0015 \pm 0.0009$ & $0.0023 \pm 0.0007$ & $\mathrm{C}^{\mathrm{c}}$ & \\
\hline$\alpha \mathrm{NTX}$ & $2.5 \times 10^{-8}$ & $0.0016 \pm 0.0006$ & & $\mathrm{C}$ & \\
\hline Nicotine & $5 \times 10^{-6}$ & $2.14 \pm 1.38$ & $0.15 \pm 0.75$ & $\mathrm{C}$ & 20 \\
\hline Carbamylcholine & $2 \times 10^{-5}$ & $3.47 \pm 1.33$ & $11.2 \pm 2.1$ & $\mathrm{C}$ & 40 \\
\hline$d$-Tubocurarine & $2 \times 10^{-5}$ & $4.12 \pm 3.98$ & $2.56 \pm 1.49$ & $\mathrm{C}$ & 1.7 \\
\hline Strychnine & $1 \times 10^{-5}$ & $6.80 \pm 2.09$ & $2.22 \pm 1.8$ & $\mathrm{C}$ & $54.0^{d}$ \\
\hline Bicuculline & $1 \times 10^{-4}$ & $10.9 \pm 6.4$ & $33.1 \pm 8.5$ & $\mathrm{C}$ & \\
\hline Atropine & $1 \times 10^{-4}$ & $51.8 \pm 36.6$ & & $\mathrm{C}$ & \\
\hline Decamethonium & $2 \times 10^{-4}$ & $151 \pm 77.6$ & $604 \pm 356$ & $\mathrm{NC}$ & 0.8 \\
\hline Neostigmine & $2.5 \times 10^{-3}$ & $484 \pm 42$ & $773 \pm 281$ & $\mathrm{C}$ & \\
\hline Hexamethonium & $1 \times 10^{-3}$ & $824 \pm 46$ & $699 \pm 176$ & $\mathrm{NC}$ & 60 \\
\hline Histamine & & $>1000^{e}$ & & & \\
\hline Glutamate & & $>1000^{e}$ & & & \\
\hline Penicillin G & & $>1000^{e}$ & $>1000^{e}$ & & \\
\hline Picrotoxin & & $>1000^{e}$ & $>1000^{e}$ & & \\
\hline Ouabain & & $>1000^{e}$ & & & \\
\hline
\end{tabular}

${ }^{a}$ Inhibition constant $\left(K_{i}\right)$ and type of inhibition for Aplysia ganglion and rat brain were determined by least squares analysis of double reciprocal plots of ${ }^{125} \mathrm{I}-\alpha \mathrm{BuTX}$ binding as a function of increasing ${ }^{125} \mathrm{I}-\alpha \mathrm{BuTX}$ concentration in the presence of the indicated concentration of ligand. See "Materials and Methods" for additional details. Results are expressed as the mean \pm SD for at least two independent experiments.

${ }^{b}$ Data taken from Weber and Changeux (1974).

" Type of inhibition for Aplysia and rat brain. C, competitive; NC, noncompetitive. See "Materials and Methods" for details.

${ }^{d}$ Determined by inhibition of the initial rate of toxin binding as described by Schmidt and Raferty (1974).

${ }^{e}$ No inhibition of ${ }^{125} \mathrm{I}-\alpha \mathrm{BuTX}$ binding was observed for these ligands at concentrations up to $1 \mathrm{mM}$.

indicated that $\alpha \mathrm{BuTX}$ blocked all ACh responses in Aplysia, and of Szczepaniak (1974), who found that $\alpha \mathrm{BuTX}$ did not affect any $\mathrm{ACh}$ responses in the snail, Helix aspersa. The basis for these discrepancies, however, remains unclear and could be due to species differences or the source and purification of $\alpha \mathrm{BuTX}$.

The major finding in our study is the demonstration that the $\alpha$-neurotoxins antagonize $\uparrow \mathrm{G}_{\mathrm{Cl}}$ responses induced by certain noncholinergic agonists (Hm, some glu, but not GABA). The specificity of the $\alpha$-toxins for $\mathrm{Cl}^{-}$conductances is further demonstrated in the specific antagonism of $\uparrow \mathrm{G}_{\mathrm{Cl}}$ components of monosynaptic PSP's in several synaptic connections. Moreover, there appears to be a correlation between the presence of an $\mathrm{ACh}$ receptor mediating an $\uparrow \mathrm{G}_{\mathrm{Cl}}$ response and the ability of toxin to block a noncholinergic $\uparrow \mathrm{G}_{\mathrm{Cl}}$ response (Fig. 5). However, to further substantiate this correlation, other neurons must be found which respond to noncholinergic agonists and transmitters with an $\uparrow \mathrm{G}_{\mathrm{Cl}}$ but lack an $\uparrow \mathrm{G}_{\mathrm{Cl}}$ response to $\mathrm{ACh}$ to see if the $\alpha$-toxins fail to antagonize these noncholinergic responses. The antagonism of the $\uparrow \mathrm{G}_{\mathrm{Cl}}$ component of the PSP mediated by the $S_{1}$ neurons, whose transmitter does not appear to be any of the transmitters identified in Aplysia, suggests that the $\uparrow \mathrm{G}_{\mathrm{Cl}}$ response to compounds other than $\mathrm{Hm}$ and glu may also be antagonized by the $\alpha$-toxins.

The ${ }^{125} \mathrm{I}-\alpha \mathrm{BuTX}$ binding data for Aplysia ganglia homogenates are remarkably similar to that for vertebrate CNS preparations (see Table I) and indicate a specific binding site with a pharmacological profile characteristic of a nicotinic cholinergic site. The nicotinic cholinergic antagonists, $\alpha \mathrm{BuTX}, \alpha \mathrm{NTX}$, and $d$-tubocurarine, as well as the agonists, nicotine and carbamylcholine, are potent competitive inhibitors of toxin binding in both Aplysia and in rat brain. In addition, three compounds, neostigmine, bicuculline, and strychnine, were found to be competitive inhibitors of ${ }^{125} \mathrm{I}-\alpha \mathrm{BuTX}$ binding in both Aplysia and in rat brain. These ligands were tested to see if they affected toxin binding because they have been shown to inhibit $\uparrow \mathrm{G}_{\mathrm{Cl}}$ responses induced by cholinergic and noncholinergic agonists in Aplysia (Kehoe, 1972b; Gerschenfeld and Paupardin-Tritsch, 1974; Faber and Klec, 1974; Yarowsky and Carpenter, 1978).

Strychnine proved to be an especially potent competitive inhibitor of toxin binding in Aplysia and in rat brain and may be a useful ligand in differentiating the CNS toxin binding site from the toxin binding site in skeletal neuromuscular junctions. Our rationale for testing

Figure 7. Concentration-dependent ability of various ligands to inhibit specific ${ }^{125} \mathrm{~T}-\alpha \mathrm{BuTX}$ binding to Aplysia ganglia homogenates. $A$, Effects of various concentrations of unlabeled $\alpha \mathrm{BuTX}, \alpha \mathrm{NTX}$, nicotine, carbamylcholine, $d$-tubocurarine, and strychnine in inhibiting ${ }^{125} \mathrm{I}-\alpha \mathrm{BuTX}$ binding. These ligands were the most potent inhibitors of toxin binding. $B$, Effects of atropine, bicuculline, decamethonium, hexamethonium, and neostigmine on ${ }^{125} \mathrm{I}-\alpha \mathrm{BuTX}$ binding. These compounds were less effective in inhibiting toxin binding. $C$, Lack of effects of noncholinergic ligands and $\mathrm{Cl}^{-}$channel blockers on ${ }^{125} \mathrm{I}-\alpha \mathrm{BuTX}$ binding. Millimolar concentrations of glu and $\mathrm{Hm}$ had no effect on toxin binding even though toxin blocks glu- and Hm-induced $\uparrow \mathrm{G}_{\mathrm{Cl}}$ responses. The $\mathrm{Cl}^{-}$channel blockers, penicillin and picrotoxin, had no effect on toxin binding at millimolar levels. The (Na+, $\mathrm{K}^{+}$)-ATPase inhibitor, ouabain, also had no effect on ${ }^{125} \mathrm{I}-\alpha \mathrm{BuTX}$ binding. See "Materials and Methods" for details. 
strychnine effects on toxin binding were based on earlier observations that strychnine and $d$-tubocurarine had similar pharmacological effects on Aplysia neurons. Both compounds antagonize $\uparrow \mathrm{G}_{\mathrm{Na}}$ and $\uparrow \mathrm{G}_{\mathrm{Cl}}$ responses to $\mathrm{ACh}$ (Kehoe, 1972b), as well as to other agonists (Faber and Klee, 1974; Carpenter et al., 1977), and are ineffective on GABA-induced $\uparrow \mathrm{G}_{\mathrm{Cl}}$ responses (Carpenter et al., 1977; Yarowsky and Carpenter, 1978). Strychnine is often classified as a glycine antagonist in the vertebrate CNS (Curtis et al., 1971), but it also has antagonist actions at several cholinergic junctions (Lanari and Luco, 1939; Alving, 1961). Although $d$-tubocurarine and strychnine appear to share many pharmacological similarities, there is an important difference in their effects on ${ }^{125} \mathrm{I}-\alpha \mathrm{BuTX}$ binding to neuronal membranes and to Torpedo electric organ. $d$-Tubocurarine is a potent competitive inhibitor of ${ }^{125} \mathrm{I}-\alpha \mathrm{BuTX}$ binding in Torpedo electric organ as well as neuronal membranes. However, strychnine is less effective in Torpedo than in Aplysia or rat brain. Strychnine may, therefore, serve as a useful ligand in differentiating neuronal ${ }^{125} \mathrm{I}-\alpha \mathrm{BuTX}$ binding sites from peripheral electric organ or skeletal muscle sites.

The efficacy of other ligands in antagonizing ${ }^{125} \mathrm{I}-$ $\alpha$ BuTX binding in Aplysia was tested in an attempt to gain some insight into the mechanism of toxin antagonism of noncholinergic $\uparrow \mathrm{G}_{\mathrm{Cl}}$ responses. $\mathrm{Hm}$ and glu do not antagonize toxin binding, which suggests that the inhibition of $\mathrm{Hm}$ and glu $\uparrow \mathrm{G}_{\mathrm{Cl}}$ responses by the $\alpha$-neurotoxins is not mediated by binding to the recognition sites for these agonists. In addition, penicillin $\mathrm{G}$ and picrotoxin, two compounds which have been designated $\mathrm{Cl}^{-}$ channel blockers, were without effect on toxin binding. Penicillin $\mathrm{G}$ has been shown to block $\uparrow \mathrm{G}_{\mathrm{Cl}}$ responses to ACh, GABA, 5HT, and dopamine in Aplysia (Pellmar and Wilson, 1977). Similarly, picrotoxin blocks the $\uparrow \mathrm{G}_{\mathrm{Cl}}$ response induced by $\mathrm{ACh}$ and GABA in Aplysia (Yarowsky and Carpenter, 1978) and has been shown by Takeuchi and Takeuchi (1969) to block $\mathrm{Cl}^{-}$channels at the crayfish inhibitory neuromuscular junction. It thus appears that the $\alpha$-neurotoxins do not inhibit noncholinergic $\uparrow \mathrm{G}_{\mathrm{Cl}}$ responses by acting as $\mathrm{Cl}^{-}$channel blockers since none of the compounds which are known to inhibit $\uparrow \mathrm{G}_{\mathrm{Cl}}$ responses, including $\mathrm{GABA} \uparrow \mathrm{G}_{\mathrm{Cl}}$ responses, has a significant effect on ${ }^{125} \mathrm{I}-\alpha \mathrm{Bu}$ TX binding.

The effective toxin concentration $\left(10^{-6}\right.$ to $\left.10^{-5} \mathrm{M}\right)$ for blocking physiological responses in Aplysia is several orders of magnitude higher than that necessary to saturate $\alpha \mathrm{BuTX}$ binding sites in membrane preparations. High concentrations of toxin are also required to block ACh responses in the chick ciliary ganglion (Chiappinelli and Zigmond, 1978; Conti-Tronconi et al., 1979) and in cat cochlea (Fex and Adams, 1978). This quantitative difference between binding and physiological effectiveness may be due to several factors inherent in the different experimental conditions used for each study. Binding studies are done with tissue homogenates, whereas physiological studies are conducted with practically intact preparations. Physiological experiments with Aplysia are conducted in a saline (ASW) containing high concentrations of salts. In a few preliminary binding studies conducted in ASW, we have observed a significantly reduced ${ }^{125} \mathrm{I}-\alpha \mathrm{BuTX}$ binding to Aplysia membranes.
An alternative explanation for the absence of a close quantitative correlation between binding studies and physiological effectiveness of toxins could be that two unrelated domains of the receptor-ionophore complex are being observed with the separate experimental approaches. This seems unlikely, however, in view of the close qualitative correspondence between the pharmacological characteristics of ${ }^{125} \mathrm{I}-\alpha \mathrm{BuTX}$ binding and the pharmacology of ACh responses in Aplysia. Of the three types of ACh-induced conductances, the $\alpha$-toxins block only the $\uparrow \mathrm{G}_{\mathrm{Cl}}$, while hexamethonium antagonizes only the $\uparrow \mathrm{G}_{\mathrm{Na}}$ ACh response. Toxin binding in Aplysia is relatively insensitive to hexamethonium, and the inhibition is noncompetitive in nature, suggesting an indirect mechanism. In contrast, $d$-tubocurarine blocks both $\uparrow \mathrm{G}_{\mathrm{Na}}$ and $\uparrow \mathrm{G}_{\mathrm{Cl}}$ responses (Kehoe, 1972b) and is a potent competitive inhibitor of ${ }^{125} \mathrm{I}-\alpha \mathrm{BuTX}$ binding. The mammalian ganglionic nicotinic acetylcholine response appears to be pharmacologically similar to the $\uparrow \mathrm{G}_{\mathrm{Na}}$ response in Aplysia in its sensitivity to blockade by hexamethonium and insensitivity to blockade by $\alpha$ BuTX (Brown, 1979). Perhaps the toxin binding sites observed in mammalian neuronal preparations are related to an $\mathrm{ACh}$ receptor mediating an $\uparrow G_{\mathrm{Cl}}$ rather than $\uparrow G_{\mathrm{Na}}$ response. In fact, one case of $\alpha$ BuTX-induced blockade of a mammalian neuronal nicotinic cholinergic response is thought to be mediated by $\uparrow \mathrm{G}_{\mathrm{Cl}}$ (Fex and Adams, 1978).

In summary, the ${ }^{125} \mathrm{I}-\alpha \mathrm{BuTX}$ binding studies characterize the toxin binding site as a nicotinic cholinergic site even though the $\alpha$-neurotoxins antagonize $\uparrow \mathrm{G}_{\mathrm{Cl}}$ responses induced by certain noncholinergic agonists and transmitters. The ineffectiveness of $\mathrm{Cl}^{-}$channel blockers (penicillin and picrotoxin) in inhibiting toxin binding suggests that the toxins are not, themselves, $\mathrm{Cl}^{-}$channel blockers. Morenver, toxin does not inhibit all $\mathrm{Cl}^{-}$-mediated responses (e.g., GABA-, certain glu-, and $\mathrm{Hm}$-induced $\uparrow \mathrm{G}_{\mathrm{Cl}}$ responses) and the antagonism of noncholinergic $\uparrow \mathrm{G}_{\mathrm{Cl}}$ responses by toxin appears to be related to the presence of an $\uparrow \mathrm{G}_{\mathrm{Cl}} \mathrm{ACh}$ response. A tenable conclusion based on these results is that the toxin inhibition of noncholinergic $\uparrow \mathrm{G}_{\mathrm{Cl}}$ responses may be mediated through a cholinergic receptor associated with the $\mathrm{Cl}^{-}$conductance mechanism for the noncholinergic agonist.

A more specific working hypothesis which would explain our observations is the possibility that the $\alpha$-neurotoxins block noncholinergic $\uparrow \mathrm{G}_{\mathrm{Cl}}$ responses because of multireceptor sharing of $\mathrm{Cl}^{-}$channels. When the $\alpha$-neurotoxins bind to the $\mathrm{ACh}$ receptors, the response of noncholinergic receptors sharing the $\mathrm{Cl}^{-}$channel are also blocked. This hypothesis predicts that, wherever toxin blocks a noncholinergic $\uparrow \mathrm{G}_{\mathrm{Cl}}$ response, an $\mathrm{ACh}$ receptor is also present and shares the $\mathrm{Cl}^{-}$response mechanism. However, not all $\mathrm{Cl}^{-}$channels may be coupled to multireceptors. This is suggested by the observation that responses to $\mathrm{ACh}$ were readily elicited from all areas of the cell soma, whereas responses to noncholinergic agonists were restricted to certain locations, and by the variability of toxin inhibition of $\uparrow \mathrm{G}_{\mathrm{Cl}}$ glu responses on cells where the $\uparrow G_{C l} A C h$ response was completely blocked by toxin. The hypothesis suggested by our observation is testable and is currently under investigation.

The generality of our observations on $\alpha \mathrm{BuTX}$ and 
$\alpha$ NTX effects in Aplysia remains to be tested in other neuronal systems. Whether another class of nicotinic $\Lambda$ Ch receptors mediating an $\uparrow \mathrm{G}_{\mathrm{Cl}}$ response exists in the vertebrate central nervous system is an intriguing possibility, especially in light of the observations of Fex and Adams (1978) that $\alpha$ Bu'TX reversibly blocks an $\uparrow \mathrm{G}_{\mathrm{Cl}}$ cholinergic response in the cat cochlea. Moreover, our hypothesis on the mechanism by which the $\alpha$-neurotoxins block noncholinergic $\uparrow \mathrm{G}_{\mathrm{Cl}}$ responses, i.e., because of multireceptor sharing of ion channels, is testable and would add an interesting dimension to our concepts of receptorionophore organization. In addition, the existence of these proposed multireceptor-ionophore mosaics at extra- and subsynaptic sites may help to explain the often confusing classification of pharmacological agents.

\section{References}

Alving, B. O. (1961) The action of strychnine at cholinergic junctions. Arch. Int. Pharmacodyn Ther. 131: 123-150.

Ascher, P., D. Kunze, and T. O. Neild (1976) Chloride distribution in Aplysia neurones. J. Physiol. (Lond.) 256: 441-464.

Ascher, P., P. Marty, and T. O. Neild (1978) Life time and elementary conductance of the channels mediating the excitatory effects of acetylcholine in Aplysia neurones. J. Physiol. (Lond.) 278: 177-206.

Brown, D. A. (1979) Neurotoxins and the ganglionic (C6) type of nicotinic receptor. In Advances in Cytopharmacology, B. Ceccarelli and F. Clementi, eds., Vol. 3, pp. 225-230, Raven Press, New York.

Carbonetto, S. T., D. M. Fambrough, and K. J. Muller (1978) Nonequivalence of $\alpha$-bungarotoxin receptors and acetylcholine receptors in chick sympathetic neurons. Proc. Natl. Acad. Sci. U. S. A. 75: 1016-1020.

Carpenter, D. O., J. W. Swann, and P. J. Yarowsky (1977) Effect of curare on responses to different putative neurotransmitters in Aplysia neurons. J. Neurobiol. 8: 119-132.

Chiappinelli, V. A., and R. E. Zigmond (1978) $\alpha$-Bungarotoxin blocks nicotinic transmission in the avian ciliary ganglion. Proc. Natl. Acad. Sci. U. S. A. 75: 2999-3003.

Conti-Tronconi, B., C. Gotti, P. Paggi, and A. Rossi (1979) Acetylcholine receptors in the ciliary ganglion and in the iris muscle of the chick: Specific binding and effect on the synaptic transmission of the neurotoxin from Naja naja siamensis. Br. J. Pharmacol. 66: 33-38.

Curtis, D. R., A. W. Duggan, and G. A. R. Johnston (1971) The specificity of strychnine as a glycine antagonist in the mammalian spinal cord. Exp. Brain Res. 12: 547-565.

Faber, D. S., and M. R. Klee (1974) Strychnine interactions with acetylcholine, dopamine and serotonin receptors in Aplysia neurons. Brain Res. 65: 109-126.

Fambrough, D. M. (1979) Control of acetylcholine receptors in skeletal muscle. Physiol. Rev. 59: 165-227.

Fex, J., and J. C. Adams (1978) $\alpha$-Bungarotoxin blocks reversibly cholinergic inhibition in the cochlea. Brain Res. 159: 440444.

Fiore, L., and J. M. Meunier (1975) A network of synaptic relations in the buccal ganglia of Aplysia. Brain Res. 92: 336340.

Fredman, S. M., and B. Jahan-Parwar (1975) Synaptic connections in the cerebral ganglion of Aplysia. Brain Res. 100: 209214.

Gardner, D. (1977) Voltage clamp analysis of a self-inhibitory synaptic potential in the buccal ganglia of Aplysia. J. Physiol. (Lond.) 264: 893-920.

Gardner, D., and E. R. Kandel (1977) Physiological and kinetic properties of cholinergic receptors activated by multiaction interneurons in buccal ganglia of Aplysia. J. Neurophysiol. 40: 333-348.

Gerschenfeld, H. M., and D. Paupardin-Tritsch (1974) Ionic mechanisms and receptor properties underlying the responses of molluscan neurones to 5-hydroxytryptamine. J. Physiol. (Lond.) 243: 427-456.

Gruol, D. L., and D. Weinreich (1979) Two pharmacologically distinct histamine receptors mediating membrane hyperpolarization in identified neurons of Aplysia californica. Brain Res. 162: 281-301.

Kehoe, J. (1972a) Ionic mechanisms of a two-component cholinergic inhibition in Aplysia neurones. J. Physiol. (Lond.) 225: 85-114.

Kehoe, J. (1972b) Three acetylcholine receptors in Aplysia neurones. J. Physiol. (Lond.) 225: 115-146.

Kehoe, J., R. Sealock, and C. Bon (1976) Effects of $\alpha$-toxins from Bungarus multicinctus and Bungarus caeruleus on cholinergic responses in Aplysia neurones. Brain Res. 107: 527-540.

Lanari, A., and J. V. Luco (1939) The depressant action of strychnine on the superior cervical sympathetic ganglion and on skeletal muscle. Am. J. Physiol. 126: 227-282.

Lee, C.- Y. (1972) Chemistry and pharmacology of polypeptide toxins in snake venoms. Annu. Rev. Pharmacol. 12: 265-286.

Lowry, O. H., N. J. Rosebrough, A. L. Farr, and R. J. Randall (1951) Protein measurement with the Folin phenol reagent. J. Biol. Chem. 193: 265-275.

McCaman, R. E., and D. McKenna (1978) Monosynaptic connections between histamine-containing neurons and their various follower cells. Brain Res. 141: 165-171.

Mebs, D., K. Narita, S. Iwanaga, Y. Samejima, and C.- Y. Lee (1972) Purification properties and amino acid sequence of $\alpha$ bungarotoxin from the venom of Bungarus multicinctus. Hoppe Seyler's Z. Physiol. Chem. 353: 243-262.

Morley, B. J., G. E. Kemp, and P. Salvaterra (1979) Minireview: $\alpha$-Bungarotoxin binding sites in the CNS. Life Sci. 24: 859872.

Ono, J. K., and R. E. McCaman (1980) Identification of additional histaminergic neurons in Aplysia: Improvement of single cell isolation techniques for in tandem physiological and chemical studies. Neuroscience 5: 835-840.

Pellmar, T. C., and W. A. Wilson (1977) Penicillin effects on iontophoretic responses in Aplysia californica. Brain Res. 136: 89-101.

Ravdin, P. M., and D. K. Berg (1979) Inhibition of neuronal acetylcholine sensitivity by $\alpha$-toxins from Bungarus multicinctus venom. Proc. Natl. Acad. Sci. U. S. A. 76: 2072-2076.

Salvaterra, P. M., and R. M. Foders (1979) $\left[{ }^{125}[]_{2} \alpha\right.$-Bungarotoxin and $\left[{ }^{3} \mathrm{I} I\right]$ quinuclidinyl-benzilate binding in central nervous systems of different species. J. Neurochem. 32: 15091517.

Salvaterra, P. M., and D. A. Matthews (1980) Isolation of a rat brain subcellular fraction enriched in putative neurotransmitter receptors and synaptic junctions. Neurochem. Res. 5: 181-196.

Schmidt, J., and M. A. Raferty (1974) The cation sensitivity of the acetylcholine receptor from Torpedo californica. J. Neurochem. 23: 617-623.

Shain, W., L. A. Greene, D. O. Carpenter, A. J. Sytkowski, and Z. Vogel (1974) Aplysia acetylcholine receptors: Blockade by and binding of $\alpha$-bungarotoxin. Brain Res. 72: 225-240.

Szczepaniak, A. C. (1974) Effect of $\alpha$-bungarotoxin and Dendroaspis neurotoxins on acetylcholine responses of snail neurones. J. Physiol. (Lond.) 241: 55-56P.

Takeuchi, A., and N. Takeuchi (1969) A study of the action of picrotoxin on the inhibitory neuromuscular junction of the crayfish. J. Physiol. (Lond.) 205: 377-391.

Weber, M., and J. P. Changeux (1974) Binding of Naja nigri- 
colis $\left[{ }^{3} \mathrm{H}\right] \alpha$-toxin to membrane fragments from Electrophorus and Torpedo electric organs. II. Effect of cholinergic agonists and antagonists on the binding of the tritiated $\alpha$ neurotoxin. Mol. Pharmacol. 10: 15-34.

Weinreich, D. (1977) Synaptic responses mediated by identified histamine-containing neurons. Nature 267: 854-856.
Wilson, W. A., M. T. Clark, and T. C. Pellmar (1977) Tris buffer attenuates acetylcholine responses in Aplysia neurons. Science 196: 440-441.

Yarowsky, P. J., and D. O. Carpenter (1978) A comparison of similar ionic responses to $\gamma$-aminobutyric acid and acetylcholine. J. Neurophysiol. 41: 531-541. 